\title{
Publisher Correction: 2D phase transitions: Freezing and melting skyrmions in 2D
}

Mathias Kläui iD

Correction to: Nature Nanotechnology https://doi.org/10.1038/s41565-020-0726-1, published online 24 June 2020.

In the version of this News \& Views article originally published online, the subject line 'CAR T cells' should have been ' $2 \mathrm{D}$ phase transitions'. This has now been corrected in all versions.

Published online: 2 July 2020

https://doi.org/10.1038/s41565-020-0745-y

๑) Springer Nature Limited 2020

\section{Publisher Correction: Memory devices and applications for in-memory computing}

Abu Sebastian (D), Manuel Le Gallo Did, Riduan Khaddam-Aljameh and Evangelos Eleftheriou

Correction to: Nature Nanotechnology https://doi.org/10.1038/s41565-020-0655-z, published online 30 March 2020.

In the version of this Review Article originally published, in Fig. $2 \mathrm{~g}$, the line connecting to ' $V_{\mathrm{DD}}$ ' on the right-hand side was mistakenly offset; the original and corrected Fig. $2 \mathrm{~g}$ are shown below. The online versions of the Review Article have been amended.

Original

g

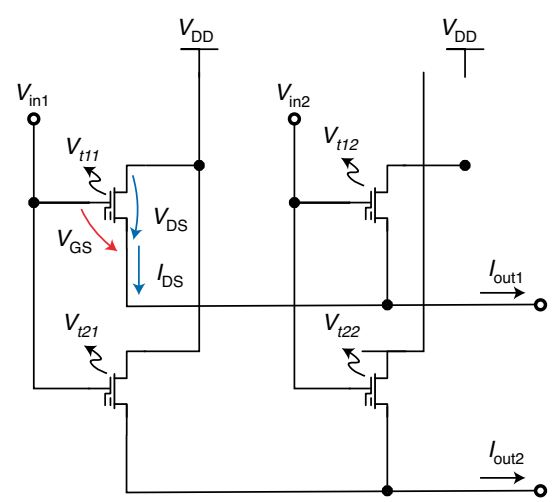

Corrected

g

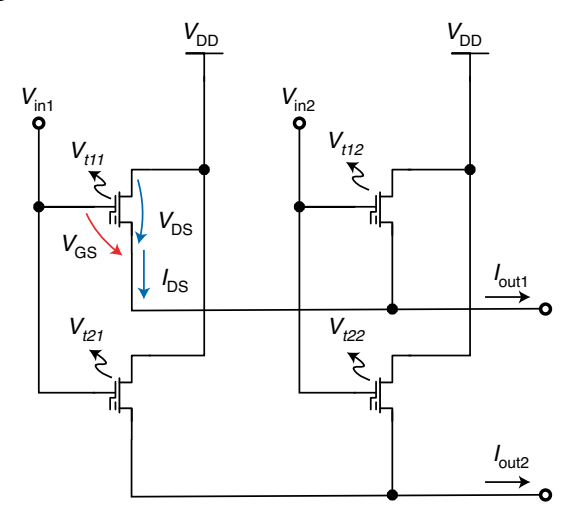

Fig. 2 | g Original and corrected.

Published online: 16 July 2020

https://doi.org/10.1038/s41565-020-0756-8

(๑) Springer Nature Limited 2020 